\title{
A narrative review of binge eating and addictive behaviors: shared associations with seasonality and personality factors
}

\author{
Caroline Davis* \\ Kinesiology and Health Sciences, York University, Toronto, ON, Canada
}

\section{Edited by:}

Astrid Müller, Hannover Medical

School, Germany

Reviewed by:

Astrid Müller, Hannover Medical

School, Germany

Katrin Giel, University Tübingen,

Germany

\section{${ }^{*}$ Correspondence:}

Caroline Davis, Kinesiology and

Health Sciences, York University, 343

Bethune College, 4700 Keele Street,

Toronto, ON M3J1P3, Canada

e-mail:cdavis@yorku.ca

\begin{abstract}
Binge-eating disorder and seasonal affective disorder were first described as clinically relevant conditions in very close temporal proximity a few decades ago. Both disorders have a higher prevalence rate in woman than in men, are characterized by a high pronenessto-stress and manifest heightened responsiveness to high-calorie, hyper-palatable foods. In recent years, a compelling body of evidence suggests that foods high in sugar and fat have the potential to alter brain reward circuitry in a manner similar to that seen when addictive drugs like alcohol and heroin are consumed in excess. These findings have led to suggestions that some cases of compulsive overeating may be understood as an addiction to sweet, fatty, and salty foods. In this paper, it is proposed that high seasonality is a risk factor for binge eating, especially in those characterized by anxious and impulsive personality traits - associations that could only occur in an environment with a superfluity of, and easy access to, rich and tasty foods. Given the well-established links between binge eating and addiction disorders [Ref. (1-3) for reviews], it is also suggested that seasonality, together with the same high-risk psychological profile, exacerbates the likelihood of engaging in a broad range of addictive behaviors. Data from a community sample $(n=412)$ of adults tested these models using linear regression procedures. Results confirmed that symptoms of binge eating and other addictive behaviors were significantly inter-correlated, and that seasonality, gender, and addictive personality traits were strong statistical predictors of the variance in binge-eating scores. Seasonality and addictive personality traits also accounted for a significant proportion of the variance in the measure of addictive behaviors. Conclusions are discussed in the context of brain reward mechanisms, motivational alternations in response to chronic over-consumption, and their relevance for the treatment of excessive appetitive behaviors.
\end{abstract}

Keywords: binge eating, addictive behaviors, seasonality, punishment sensitivity

\section{INTRODUCTION}

The identification, classification, and clinical symptomatology of psychiatric disorders - even their very existence in some cases are greatly influenced by prevailing social and economic factors. Consider, for example, the seemingly endless chronicle of Hysteria, which began many centuries ago, and then re-emerged in mid to late nineteenth century Europe as an exceedingly prominent syndromic study in medical science. It also garnered a great deal of public attention at the time (4). Hysterical symptoms like paralyzes and anesthesias were generally thought to stem from "unacceptable sexual impulses that were repressed to avoid unbearable anxiety and [were then] converted into physical symptoms" [Ref. (5), p. 534]. Hysteria was also viewed entirely as a "woman's disease" whose cause was mostly impugned on the dominant Victorian morality of sexual prudery and constraint. ${ }^{1}$ A century later, Hysteria, as a discrete psychiatric entity, was largely discredited, and

${ }^{1}$ Interestingly, some have argued that the prim sexual mores of the Victorians were merely "uttered" sentiments and imitated largely for the sake of appearance, while removed from the Diagnostic and Statistical Manual (DSM III) in 1980 (7). Soon thereafter, recognition of two other, more modern "women's diseases" began to emerge. Like Hysteria, the establishment of Seasonal Affective Disorder (SAD) and Binge-Eating Disorder (BED) as legitimate psychopathologies has been shaped by contemporaneous sociocultural and environmental pressures, and anchored to historical events and contingencies.

Although seasonal mood disturbances had been recognized for millennia, SAD was not formally described and labeled until 1984 (8). A short time later, it was introduced in the DSM-III-R (9) as a "seasonal pattern" modifier to be applied to recurrent mood disorders like major depressive disorder. In addition to the rumination and negative affect seen in all mood disorders, SAD was preeminently characterized by pronounced vegetative symptoms - the so-called "hallmark" physiological signs such as anergia, increased appetite, and weight gain - that emerge in the autumn/winter and

their actual sexual behaviors - at least among the privileged classes - were marked by considerable freedom, and even license (6). 
begin to remit in the spring (10). Many individuals with SAD also experience pronounced food cravings and frequent incidents of binge eating during the winter months $(11,12)$. Notably, however - and unlike other forms of unipolar depression - SAD occurs predominately in premenopausal adult women, and those working outside the home $(13,14)$. Most authorities agree that SAD reflects the high end of a normal human trait - seasonality - which describes the mood and behavior changes that occur across the seasons (15) and are manifest most prominently among those living in the temperate regions of the world. For thousands of generations, fluctuating patterns of food availability characterized the life of early hominins in these regions, and likely induced selective pressures on the genes responsible for food intake and energy conservation (16).

By the early 1990s, clinicians had also begun to recognize other patients with compulsive-overeating problems whose symptoms were quite similar to those seen in bulimia nervosa, but with the marked difference that their binge-eating episodes were not followed by any calorie-sparing or inappropriate compensatory behaviors (17). In other words, their binge eating occurred in the absence of hunger and deprivation, and typically involved the ingestion of large quantities of sweet and fatty foods in a relatively short period of time, with a strong feeling of loss-of-control over their food intake. This newly identified syndrome (BED) was known early on to have strong links with obesity (18) and mood disorders (19). Those with BED also display a more negative pattern of everyday emotions compared to their non-binging counterparts (20). BED was quick to make its way into the newly revised DSM-IV (21) in the Eating Disorder Not Otherwise Specified category, and soon afterward was listed in the Appendix of the DSM-IV-TR (22) as "a diagnosis for further study." Twenty years later - in the recently released DSM-5 (23) - its status has been elevated to a fully recognized mental illness. Especially notable, and similar to the pronounced sex-bias in the prevalence of SAD, is evidence that lifetime prevalence of $\mathrm{BED}$ is estimated to be about twice to six-times more common in women (depending on the country surveyed), and to occur more frequently in mature adult women than in those of younger age (24).

In this paper, it is proposed that high seasonality is a risk factor for chronic and compulsive overeating, especially in those characterized by anxious- and stress-prone personality traits - associations that could only occur in an environment with a superfluity of, and easy access to, highly palatable food resources. Given the well-established links between binge eating and addiction disorders [Ref. (1-3) for reviews], it is also suggested that seasonality, together with the same high-risk psychological profile, exacerbates the likelihood of engaging in a broad range of addictive behaviors (see Figure 1). While it is widely agreed that the development of clinically relevant psychopathologies depends considerably on factors unique to the individual, these are almost certainly aggravated by relevant environmental pressures and circumstances. The next section will describe some salient aspects of the sociopolitical landscape in Western nations during the time period when severe seasonal depression and chronic binge eating were declared "mental illnesses," and which likely contributed to the emergence of, and impairment caused by, the troubling symptoms of these conditions. Following that, evidence-based inter-connections among

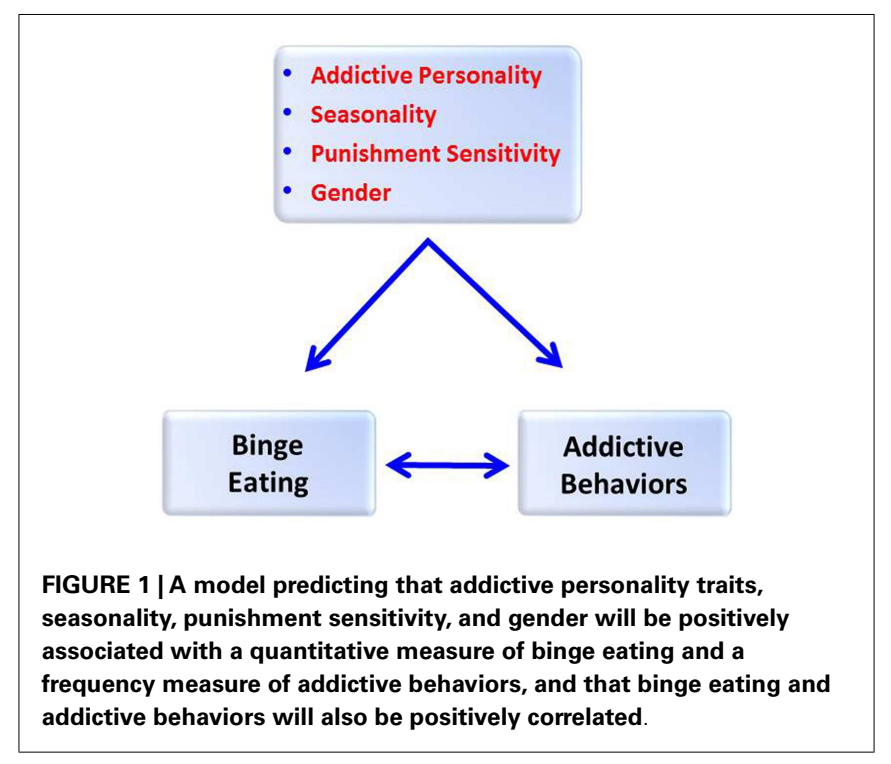

seasonality, binge eating, and addictive behaviors will be reviewed. The penultimate section of the paper provides a description of, and empirical support for, the model proposed in Figure 1.

\section{SOCIOCULTURAL AND ENVIRONMENTAL INFLUENCES}

A few decades ago, a groundswell of striking political and economic events occurred that coalesced temporally, and played a significant role in the two emerging psychiatric disturbances described above - SAD and BED. They did so mainly by providing a social backdrop, which interfaced mal-adaptively with certain individual (risk) characteristics. For example, a global surge in the prevalence of obesity began - almost concurrently in most high-income countries - in the 1970s and 1980s (25), and continued to rise steadily during the following decade (26). Illustrated by recent data from a wide range of nations, representing considerable diversity in economic development, it is especially striking that there is now a $50 \%$ greater prevalence of obesity in women than in men (27). There is also some evidence that for women, but not men, the prevalence of obesity increased the most in the years from 1986 to 1994 (28). While many factors have contributed to the population weight gain, the most proximal include a reduction in the time-cost of production and transportation across the global food system (25), and the markedly "toxic" food environment exemplified by the caloric density and hyper-palatability of the processed products that comprise a substantial proportion of the modern $\operatorname{diet}(29)$.

Another impactful social phenomenon - occurring at about the same time - was the tremendous influx of women into the workforce (30). By the early 1980s more than half the (preretirement aged) women in the US were working outside the home. And, the large majority of these were married women in their middle adult years who were engaged in full-time employment (31). While this "remarkable revolution" (32) brought considerable economic empowerment to women - never experienced before to such a degree - it also came at a personal and social cost. The concurrent and accelerated increase in the elderly population resulted in working women often being the principal 
caregivers to dependent and aged parents as well as to their own children, and in some cases grandchildren - an occurrence of considerable burden and responsibility for these "women in the middle" (33). Moreover, divorce rates hit 50\% for the first time in the early 1980s and women typically bore the brunt of single parenthood (34).

The 1980s saw the burgeoning of other social trends that had a considerable impact on women, and their psychological wellbeing. The iconic image of women's bodies decreased significantly in size in the 1980s and 1990s, as depicted, for example, by the fashion media and the number of magazine covers showing fullbody shots of women (35). A related development also occurred in the 1980s with the emergence of the commercial market of the women's fitness and exercise industry - spearheaded by Jane Fonda and her workout books and videos. The "home exercise" media gave women a glamorized approach on how to burn calories and sculpt muscles, and had a great impact on forming public opinion about women, their bodies, and the virtues of ultra-slenderness (36). By the mid 1980s, the female readership of media pertaining to diet and exercise outnumbered that of men by a ratio of about 2:1 (36).

\section{IMPACT ON MODERN “WOMEN'S DISEASES”}

It is not difficult to see how the dramatic social, economic, and environmental changes that occurred in the last few decades of the twentieth century have played a role in the emergence of modern "women's diseases" like BED and SAD. For instance, one of the most incompatible aspects of seasonality for the modern women is that increased appetite and food cravings are highly undesirable occurrences in societies that place a high value on an ultra-thin body ideal (10). These physiological changes are especially problematic and likely to contribute to substantial weight gain in the modern food environment with its superfluity of highly caloric and hyper-palatable foods. Another is that the time-and-energy demands on women who work outside the home, and who are also caregivers to children and elders, are elevated in a previously unprecedented way. Such roles are greatly incompatible with the anergy and social withdrawal that characterizes those with high levels of seasonality.

Consequent on the exigencies that compete for their time and energy, some vulnerable women experience high levels of stress in the face of inadequate resources to cope adaptively. Sex differences in the psychobiology of stress are now well-established with females producing a stronger HPA response than males. Individual differences in progesterone $(\mathrm{P})$ levels in women appear to be one factor mediating this relationship. For instance, high $\mathrm{P}$ levels have been associated with lower stress and cue-induced craving, anxiety, and cardiovascular reactions (37). This effect may occur because $\mathrm{P}$ is a potent positive enhancer of GABA receptors, and GABA is an inhibitory neurotransmitter which diminishes dopamine, reducing stress responses, drug reward, and drug cravings (37).

We have learned that stress is strongly linked to binge eating, both as an initiating and as an exacerbating factor (38, 39). Evidence also suggests that different kinds of stressors produce distinct effects on food intake in females - specifically, that psychosocial adversity tends to augment consumption of highly palatable food (40), while interoceptive stress has the opposite effect (41). It is therefore relevant that women tend to display a greater preference for sweet foods compared to their male counterparts (42) - similar to the preclinical findings in male and female rats (43) - and they are more likely to experience food cravings (44). Research has also consistently shown that chronic intake of highly palatable food can produce dopamine signaling changes in the brain which promote binge-like patterns of consumption over time (45). In other words, the easy availability of hyper-palatable food, which has occurred during the period of rapid increases in obesity rates, is an important environmental precursor of BED. Not surprisingly, therefore, binge eating is significantly greater in women than in men (46), and the most pronounced increases in morbid obesity have also occurred in women (47). In a food environment with a superfluity and ubiquity of sweet and fatty cuisine, and in a social environment with immense emotional and time demands, it is not difficult to understand the emergence of compulsive-overeating behaviors prompted both by physiological factors, and by the use of "comfort food" to self-medicate a disturbed affect (48).

Stress is also strongly implicated in the development and perpetuation of drug and alcohol use and abuse, and has a critical role in the risk for relapse in addicted individuals $(38,49-52)$. While historically drug addiction was more prevalent in men than in women (53), there is evidence that the gap is narrowing, and that earlier disparities may simply reflect variation in opportunity and gender-role expectations rather than differences in vulnerability $(54,55)$. Indeed, many addiction risk factors appear to be more pronounced in women than in men. For instance, women tend to increase their rate of drug consumption more quickly than men, are more likely to relapse, and to have longer periods of drug use before their next attempt to quit $(56,57)$. Women with addictions also report more pronounced cravings and subjective drug effects than their male counterparts (58).

\section{BINGE EATING, ADDICTIVE BEHAVIORS, AND SEASONALITY}

In considering the relationship between binge eating and addictive behaviors, there are various possible causal routes of association. For instance, from a clinical and a psychobiological perspective, BED may reflect an eating-related manifestation of some underlying pathology that is shared among all addiction disorders. Inherent in that perspective is the precept that BED is an "addiction to hyper-palatable food.” Indeed, addiction-related processes are relevant to BED since this disorder has been associated with enhanced activation of brain reward pathways $(59,60)$ and with loss-of-control intake (61). On the other hand, BED and addiction disorders may simply be co-morbid conditions like schizophrenia and smoking in the manner that one syndrome serves as a risk factor for the other. Alternatively still, there may be other lurking influences, with significant causal links both to BED and to addiction disorders, which contribute to, or even account for, their co-occurrence. In this section of the paper, research related to these various viewpoints will be reviewed, including their conjoint association with seasonality.

\section{COMMON UNDERLYING RISK FACTORS}

Some claim that current views on risks for mental illnesses have largely ignored the impact of the social and emotional world in 
which we currently live. Scheff (62), for example, has argued that modern Western society is built on a base of individualism, which has resulted in the "suppression of the social-emotional world in favor of thought and behavior" (p. 88). He explains that shame is one of the master emotions, but that the social alienation pervading our societies has created a forceful taboo on shame - in other words, we learn to be "ashamed" of our shame. The role of shame in BED is well-established. Indeed, it is integrated in the DSM diagnostic criteria for this disorder as "feelings of guilt, embarrassment, or disgust and [the individual] may binge eat alone to hide the behavior." Other clinical research found that various negative emotions related to, and including, shame had the highest probability of leading to binge-eating behavior (20). A recent experimental study also demonstrated that individuals who reported feelings of shame found a buffet meal more desirable and were more likely to binge eat (63). They also ate more than control participants in a comparative taste test. Relatedly, shame-proneness has shown replicable relationships with drug use and abuse, largely as a means of coping with negative affect states $(64,65)$.

The risk for developing stress-related behavioral disorders like BED and addictions are also exacerbated in those who are less able to endure the subjective feelings of negative mood states (6668). Low distress tolerance is a complex trait that reflects several characteristics including a lack of persistence with tasks that elicit psychological or physical discomfort, and the strong desire to do anything to prevent or stop feeling upset (69). It is seen as an emerging risk factor for various forms of psychopathology - most notably addiction disorders - and has considerable conceptual overlap with constructs like harm avoidance and punishment sensitivity. In turn, personality characteristics clearly interact with powerful environmental factors such as availability, cost, legal sanctions, and a host of attitudes and expectancies, which tend either to foster or to inhibit the use of addictive behaviors.

While emotional and personality traits can clearly be learned and shaped by environmental forces, they also have a pronounced biological basis to their development. Evidence from populationbased transmission studies suggests that common genetic factors and physiological processes contribute to the abuse of a wide array of addictive substances (70). For instance, an inability to change one's behavior when it leads to aversive consequences is a symptom common to all addiction disorders, and tends to reflect medial prefrontal cortical processes that are not functioning optimally (71). Correspondingly, such maladaptive responding is a key characteristic of those who suffer from compulsive overeating (72). Indeed, there is a rich body of evidence suggesting that BED is a specific phenotype of obesity with increased food-related impulsivity $(59,73)$ and executive-functioning deficits contributing to poor problem solving and decision making, and to cognitive inflexibility $(3,74)$.

Addictive behaviors also tend to be linked temporally and typically do not occur in isolation across the lifespan (75). It is relevant, therefore, that BED is associated with substantial psychiatric comorbidities, especially those related to substance abuse and mood and anxiety disturbances (76). There is also good evidence that excessive food consumption and substance abuse both vie for similar neural pathways, and both cause similar reward dysfunction via receptor down-regulation in the dopamine pathways (77).
Importantly, and based on data from a family history study of the relatives of women with BED, it was concluded that virtually all the disorders co-morbid with BED followed a pattern of independent transmission except for substance abuse, in which the transmission pattern indicated a shared etiology with BED and a common mechanism of vulnerability (78). However, BED patients with a parental history of substance abuse appear to be a distinct sub-type of the disorder with a developmental profile characterized by an earlier age of onset and a more rapid progression. They are also more likely to have started binge eating before they began to diet, and more likely to meet the diagnostic criteria for a mood disorder (79). Other etiologic links have been demonstrated between overeating and alcohol use. For instance, women with a family history of alcoholism had almost double the odds of being obese compared to those without a family history - a statistical association that remained robust after controlling for a number of well-established covariates of obesity (80). While this relationship was seen in men as well, it was not as strong as in women.

\section{ADDICTION TO HYPER-PALATABLE FOODS}

An increasing number of researchers and clinicians now subscribe to the view that compulsive-overeating shares explicit similarities with substance-abuse disorders, and therefore can be conceptualized as an addiction - at least in some cases $(2,3,81,82)$. Initially, the food-addiction concept earned its scientific credibility from compelling preclinical evidence that a syndrome remarkably similar to drug dependence can be very successfully induced in animals when they are given access to sugar (83). Rodent studies of food addiction have burgeoned in the past decade, and typically use behavioral paradigms based on experimentally inspired analogs of the DSM-IV-TR (22) criteria for substance dependence to demonstrate pronounced behavioral and physiological similarities between excessive drug use and diets high in sugar, fat, or both (1).

Clinical food-addiction research is sparser and more recent, and has relied, almost entirely, on studies using the Yale Food-Addiction Scale [YFAS] to establish classification (84). This assessment tool employs the DSM-IV-TR criteria for substance dependence as a template for diagnosis. To date, studies have found substantial diagnostic overlap or co-morbidity (approximately $50 \%$ ) between BED and YFAS food addiction, in addition to many shared psychological and biological risk factors $(1,85,86)$. An even greater overlap was found in an earlier study of women diagnosed with BED (87) where $92 \%$ of the sample met the DSM-IV-TR criteria for substance dependence when the word "food" was substituted for "drug" in the interview questions. A recent qualitative study of obese women with BED has also confirmed that a high proportion endorsed DSM symptoms of substance dependence when food was the "substance" in question (88). These women felt that "lossof-control" overeating, the inability to stop this behavior despite strong wishes to do so, and extreme cravings were the characteristics of their disorder which most resembled an addiction. Importantly, they emphasized that it was only highly palatable "junk" foods that elicited these feelings. This last point endorses the criticism that "food addiction" is a poorly descriptive label for cases of compulsive and impairing overeating. More apt terminology may be hyper-palatable food addiction or sugar/fat/salt addiction. 


\section{BED AND FOOD ADDICTION: A CONTINUUM OF SEVERITY}

When assessing the established animal models of food addiction, an important observation is that a pattern of compulsive intake - behaviorally similar to what we call binge eating in the human condition - is an universal feature (1). In other words, animals do not display the cardinal symptoms of addiction disorders, without also showing binge-like consumption of the experimental food. Moreover, all animal models require the introduction of highly palatable foods - that is, compulsive intake does not occur in response to the bland chow animals are normally fed. Based on these preclinical findings, and also on the pronounced clinical and phenotypic overlap between those with a diagnosis of BED and those with a YFAS-diagnosis of food addiction, we have proposed that food addiction is not a separable entity from BED but rather that it reflects - at least in many cases - a more severe and more compulsive sub-type of BED. In a recent study, preliminary support was found for this hypothesis (89). We compared two equivalent groups of overweight men and women with BED - one with co-occurring YFAS-diagnosed food addiction and the other without. While the two BED groups were equivalent in age and BMI, those with food addiction were significantly more likely to overeat for emotional and cue-driven reasons, they had more severe binge eating and food cravings, and they were more responsive to the rewarding properties of food. This group also had more addictive personality traits, was more impulsive, and had greatly elevated symptoms of depression compared to their BED counterparts without co-occurring food addiction. These findings converge with a related study of food addiction in BED patients where the number of YFAS symptoms correlated positively with Beck depression ratings, poor self-esteem, and difficulties in emotion regulation, as well as with frequency of binge episodes (86). Similarly, in a study of weight-loss treatment-seeking adults, YFAS symptom scores related significantly to increased depression, increased emotional and binge eating, and to less weight loss after several weeks of treatment (90).

In our study (89), we also compared the BED group without food addiction to a weight- and age-matched group of adults without BED and without food addiction on the same variables described above. By contrast to the earlier comparisons, these two groups were remarkably similar to each other except, not surprisingly, that the BED group reported more frequent binge eating, elevated food cravings, and greater hedonic responses to food than the non-BED controls.

\section{SEASONALITY AND ADDICTIVE BEHAVIORS}

Human biological functioning is profoundly dependent on the daily rotation of the earth on its axis, and its annual trek around the sun. Due to factors such as shift work, long work hours, extended commutes, and around-the-clock global communication, the recent imposition of a " $24 / 7 / 365$ culture" has been causally implicated in a broad range of pathologies including depression, insomnia, obesity, and immune impairment (91).

Neurons in the suprachiasmatic nucleus of the hypothalamus comprise the body's so-called "master clock," which regulates the temporal organization of many human behaviors like sleeping and wakefulness (92). As part of this process, the brain's pineal gland discharges the hormone melatonin at night to promote sleep and other cyclical physiological events. The circadian system also fosters seasonal changes because of its ability to measure changing photoperiod across days of the year (93). In other words, we have an endogenous temporal program that uses daylight as an entraining cue (91). Across the population, however, there is great variation in photo-responsiveness with some being highly photoperiodic, others not at all, and a range of intermediate types (94).

Various family and genetic studies have demonstrated a biological link between seasonality/SAD and drug-abuse disorders like alcoholism $(95,96)$. For example, genes that have a regulatory role in the circadian pacemaker system have also been associated with the consumption, sensitivity, and abuse of alcohol (97). Other evidence also supports seasonal trends in the use of various addictive substances with significant peaks in the winter and a diminution in the summer months $(98,99)$. Relatedly, links between drug use and depression become stronger with increasing latitude (93). And finally, there is evidence that addiction may be more prevalent in those with a compromised "master clock" and/or with mood disorders that have a circadian basis (100). As was discussed earlier in this paper, there are also established links between BED and SAD. Interestingly, therefore, a study of Google internet queries across all major mental health disorders over a 5-year period from 2006 to 2010 followed a pattern of winter peaks and summer troughs, with these seasonal differences being most pronounced for disordered eating (101).

\section{A PROCESS MODEL LINIKING SEASONALITY, PSYCHOLOGICAL VULNERABILITY, AND GENDER TO BINGE EATING AND ADDICTIVE BEHAVIORS}

In summary, this paper has reviewed evidence linking binge eating and addictive behaviors, and has identified stable psychological traits including seasonality and proneness-to-stress as common vulnerabilities. To date, no research has assessed the cumulative risk potential of these factors for binge eating and other addictive behaviors. Figure 1 describes two models proposing, on the one hand, that addictive personality traits, punishment sensitivity, and high seasonality each contribute unique variance to symptom scores for binge eating, and on the other hand, that these variables would also contribute to the variance in a composite measure of addictive behaviors. Gender was added to both models to assess male-female differences. We also predicted that binge eating and addictive behaviors would be positively and significantly inter-correlated.

\section{PARTICIPANTS}

A community-based sample of adult men $(n=103)$ and women $(n=321)$ between the ages of 25 and 50 years, and representing a broad range of body weights $(\mathrm{BMI}=32.3$; $\mathrm{SD}=9.4)$, were recruited for the study. Participants were fluent in English and had lived in North America for at least 5 years prior to their enrollment. Exclusion criteria included a current diagnosis of any psychotic disorder, addiction disorder, a serious medical/physical illness such as cancer or heart disease, or the use of medication with a high probability of affecting appetite like stimulants or neuroleptic drugs. Participants were recruited from posters located at a variety of public institutions. Advertisements were also placed 
in local newspapers and various online sites. All measures were assessed individually in a hospital research laboratory. The procedures employed in this study were approved by the university Research Ethics Board, and were carried out in accordance with the Declaration of Helsinki. As an initial step in the screening procedure, a short telephone interview was carried out to confirm basic eligibility criteria before the in-person assessment appointment took place. During this appointment, height and weight were measured with participants wearing light indoor clothing and standing in stocking feet.

\section{MEASUREMENTS}

Binge Eating was assessed by 5-items of the Binge-Eating Questionnaire (102), which obtains information about frequency and severity of symptoms such as loss-of-control over eating, and negative affect following a binge. The alpha coefficient for this study was 0.85 .

Addictive Behaviors were assessed by the Shorter PROMIS Questionnaire (103), a self-report instrument for the concurrent measurement of 16 addictive and/or excessive behaviors. The scale items reflect common characteristics of addictive behaviors such as using more than was intended and increased capacity or tolerance. For the purpose of this study, a total score was created by summing the items for the following six subscales: caffeine, recreational drugs, sex, nicotine, shopping/spending, and alcohol. Other subscales were deemed insufficiently related to conventional addiction disorders to be included. Only a subgroup of the sample $(n=211)$ completed this measure. The alpha coefficients for the six subscales ranged from 0.80 to 0.97 .

Addictive Personality Traits were assessed by the 32-item Addiction Scale of the Eysenck Personality Questionnaire-Revised (EPQ-R) (104). This well-validated addiction-proneness scale was derived empirically by identifying items of the EPQ-R, which significantly differentiated those with drug addictions from normal controls. The selected items largely reflect impulsiveness, anxiousness, and negative affect. The Cronbach alpha coefficient in the present study was 0.79 .

Seasonality was assessed by the Seasonal Pattern Assessment Questionnaire (SPAQ) (105). The Global Seasonality Score (GSS) is the sum of six items (0-4) asking about seasonal changes in sleep length, social activity, mood, weight, appetite, and energy. Higher scores reflect greater seasonality. The GSS is the most frequently used dimensional measure of seasonality and has demonstrated good psychometric properties (15). The GSS alpha coefficient for our study was 0.87 .

Sensitivity to Punishment (SP) was assessed by 24 binary items of the SP Sensitivity to Reward Questionnaire reflecting the respondent $=\mathrm{s}$ avoidance responses under conditions of punishment (106). This sub-scale was developed to evaluate variation in a neurobiological motivational system - known as behavioral inhibition - alleged to underlie anxiousness and distress sensitivity. The alpha coefficient for the present study was 0.87 .

The data were analyzed using stepwise regression procedures with punishment sensitivity, addictive personality traits, seasonality, and gender entered as independent variables. In the first model, binge eating was the dependent variable. Results demonstrated that the three psychological independent variables each
Table 1 | Hierarchical regression analysis summary $(n=412)$ for the independent variables (punishment sensitivity, addictive personality, seasonality, and gender) predicting the dependent variable (binge-eating symptom scores).

\begin{tabular}{lcrrcc}
\hline Variable & $\boldsymbol{B}$ & SEB & $\boldsymbol{t}$ & $\boldsymbol{p}$ & $\boldsymbol{R}^{\mathbf{2}}$ change \\
\hline $\begin{array}{l}\text { Step 1 } \\
\text { Punishment sensitivity }\end{array}$ & 0.14 & 0.02 & 9.73 & $<0.0001$ & 0.187 \\
Step 2 & & & & & \\
Punishment sensitivity & 0.09 & 0.02 & 5.15 & $<0.0001$ & \\
Addictive personality & 0.09 & 0.02 & 4.85 & $<0.0001$ & 0.044 \\
Step 3 & & & & & \\
Punishment sensitivity & 0.09 & 0.02 & 5.03 & $<0.0001$ & \\
Addictive personality & 0.08 & 0.02 & 3.88 & $<0.0001$ & \\
Seasonality & 0.05 & 0.02 & 3.06 & 0.002 & 0.017 \\
Step 4 & & & & & \\
Punishment sensitivity & 0.08 & 0.02 & 4.72 & $<0.0001$ & \\
Addictive personality & 0.08 & 0.02 & 4.13 & $<0.0001$ & \\
Seasonality & 0.05 & 0.02 & 2.99 & 0.003 & \\
Gender & -0.52 & -0.19 & -2.76 & 0.006 & 0.014 \\
\hline
\end{tabular}

Total $R^{2}=0.26$

contributed a significant proportion of the variance to the dependent variable, and that females had higher scores than males. Together these variables accounted for $26 \%$ of the variance in binge-eating scores. Summary statistics are shown in Table 1. In the second analysis, the addictive-behaviors measure was regressed on the same four independent variables. Only addictive personality traits and seasonality were significant predictors in the model, and together accounted for $19 \%$ of the variance in the dependent variable (see Table 2). Finally, and as hypothesized, the correlation between binge eating and addictive behaviors was highly statistically significant and of virtually identical magnitude in women $(r=0.43)$ and men $(r=0.45)$. Collectively, these findings support the conjoint relationship between binge eating and the use of other addictive behaviors, and they endorse the view that seasonality and addictive personality traits - the latter of which reflect elevated levels of emotional reactivity, proneness-to-stress, impulsivity, and negative affect - are common risk factors for both potentially pathological behaviors.

\section{CONCLUSIONS}

In the opinion of this author, the evidence is irrefutable that compulsive overeating - what we call BED in some cases, or food addiction in others - is very similar to what is understood by terms like "drug abuse" and "substance dependence." These are all labels which acknowledge that chronic over-consumption of rewarding substances, and thereby excessive stimulation of a core mechanism of human survival - the brain's common reward pathway - diminishes our ability to function with full capacity for reason and free will. What we choose to call this dysfunction is perhaps less important than finding appropriate treatment and restorative measures for individuals who suffer from the condition.

All psychiatric disorders, including drug abuse and behavioral addictions, have a relatively low base-rate occurrence, even though the related symptoms exist along a continuum of severity across 
Table 2 | Hierarchical regression analysis summary $(n=211)$ for the independent variables (punishment sensitivity, addictive personality, seasonality, and gender) predicting the dependent variable (addictive behaviors).

\begin{tabular}{lccccc}
\hline Variable & $\boldsymbol{B}$ & SEB & $\boldsymbol{t}$ & $\boldsymbol{p}$ & $\boldsymbol{R}^{\mathbf{2}}$ change \\
\hline Step 1 & & & & & \\
$\begin{array}{l}\text { Addictive personality } \\
\text { Step 2 }\end{array}$ & 2.93 & 0.45 & 6.50 & $<0.0001$ & 0.167 \\
$\begin{array}{l}\text { Addictive personality } \\
\text { Seasonality }\end{array}$ & 2.58 & 0.47 & 5.48 & $<0.0001$ & \\
Excluded variables & 1.07 & 0.46 & 2.32 & 0.021 & 0.021 \\
Gender & & & & & \\
Punishment sensitivity & & & 1.00 & 0.319 & \\
& & & 0.20 & 0.839 & \\
\hline
\end{tabular}

Total $R^{2}=0.19$

individuals in the population. Therefore, most people who use addictive substances - drugs or highly palatable food - do not develop dependence. Nevertheless, gaining a better understanding of the sequelae of behaviors such as overeating is highly pertinent because these activities are known to cause alterations in brain reward functioning and to reduce sensitivity in these pathways. They are also highly likely to cause weight gain over time. Developing health-related behavioral strategies that recognize changes in motivation as a consequence of excessive food consumption are also important because of evidence that brain neuro-adaptations can increase the likelihood of using and abusing other addictive substances (107). Avena and her colleagues (107) have argued, for a number of reasons, that such treatment approaches are particularly important for the growing cohort of middle-age and elderly adults in the population. First of all, a reduction in dopamine reward functioning is a normal process of aging (108). Additionally, rates of obesity and of substance abuse are currently on the rise in this group, suggesting that these individuals may be at greater risk for developing a dependence on rewarding substances than are younger adults. From a treatment perspective, it is also important to take account of seasonal variation in the symptoms of binge eating and addictive behaviors in order to provide appropriate coping strategies for those who have pronounced negative changes in mood and behavior during the dark months of the year.

\section{REFERENCES}

1. Davis C. From passive overeating to "food addiction": a spectrum of compulsion and severity. ISRN Obes (2013) 2013:435027. doi:10.1155/2013/435027

2. Davis C, Carter JC. Compulsive overeating as an addiction disorder: a review of theory and evidence. Appetite (2009) 53:1-8. doi:10.1016/j.appet.2009.05.018

3. Volkow ND, Wang G-J, Tomasi D, Baler RD. The addictive dimensionality of obesity. Biol Psychiatry (2013) 73:811-8. doi:10.1016/j.biopsych.2012.12.020

4. Gilman SL, King H, Porter R, Rousseau GS, Showalter E. Hysteria Beyond Freud. Berkeley: University of California Press (1993).

5. Gordon E, Kraiuhin P, Kelly P, Meares R. The development of hysteria as a psychiatric concept. Compr Psychiatry (1984) 25:532-7. doi:10.1016/0010440X(84)90053-1

6. Peckham M. Victorian counterculture. Vic Stud (1975) 18:257-76.

7. American Psychiatric Association. Diagnostic and Statistical Manual. 3rd ed. Washington: APA (1980).

8. Rosenthal NE, Sack DA, Gillin JC. Seasonal affective disorder: a description of the syndrome and preliminary findings with light therapy. Arch Gen Psychiatry
(1984) 41:72-80. doi:10.1001/archpsyc.1984.01790120076010

9. American Psychiatric Association. Diagnostic and Statistical Manual-Revised. 3rd ed. Washington: APA (1987).

10. Davis C, Levitan RD. Seasonality and seasonal affective disorder (SAD): an evolutionary viewpoint tied to energy conservation and reproductive cycles. J Affect Disord (2005) 87:3-10. doi:10.1016/j.jad.2005.03.006

11. Donofry S, Roecklein K, Miller M. Association of DRD4 7R and DRD2 Taq1A polymorphisms with binge eating in patients with seasonal affective disorder. Behav Genet (2011) 41:903.

12. Levitan RD, Masellis M, Basile VS, Lam RW, Kaplan AS, Davis C, et al. The dopamine-4 receptor gene associated with binge eating and weight gain in women with seasonal affective disorder: an evolutionary perspective. Biol Psychiatry (2004) 56:665-9. doi:10.1016/j.biopsych.2004.08.013

13. Eagles JM. Seasonal affective disorder. Br J Psychiatry (2003) 182:174-6. doi:10.1192/bjp.182.2.174

14. Rosenthal NE. Issues for DSM-V: seasonal affective disorder and seasonality. Am J Psychiatry (2009) 166:852-3. doi:10.1176/appi.ajp.2009.09020188

15. Young MA, Blodgett C, Reardon A. Measuring seasonality: psychomotor properties of the seasonal pattern assessment questionnaire and the inventory for seasonal variation. Psychiatry Res (2003) 117:75-83. doi:10.1016/S01651781(02)00299-8

16. Siervo M, Wells JCK, Cizza G. Evolutionary theories, psychological stress and the modern obesity epidemic. Obes Metabol (2008) 4:131-42. doi:10.1002/rcm. 3841

17. Devlin MJ, Walsh BT, Spitzer RL, Hasin D. Is there another binge eating disorder - a review of the literature on overeating in the absence of bulimianervosa. Int J Eat Disord (1992) 11:333-40. doi:10.1002/1098-108X(199205) 11:43.0.CO;2-K

18. Spitzer RL. Nonpurging bulimia nervosa and binge eating disorder. Am J Psychiatry (1991) 148:1097.

19. Yanovski SZ, Nelson JE, Dubbert BK, Spitzer RL. Association of binge-eating disorder and psychiatric comorbidity in obese subjects. Am J Psychiatry (1993) 150:1472-9.

20. Zeeck A, Stelzer N, Linster HW, Joos A, Hartmann A. Emotion and eating in binge eating disorder and obesity. Eur Eat Disord Rev (2011) 19:426-37. doi:10.1002/erv.1066

21. American Psychiatric Association. Diagnostic and Statistical Manual-Revised. 4th ed. Washington: APA (1994).

22. American Psychiatric Association. Diagnostic and Statistical Manual-RevisedText Revision. 4th ed. Washington: APA (2000).

23. American Psychiatric Association. Diagnostic and Statistical Manual-5. 5th ed. Washington: APA (2013).

24. Smink RE, van Hoeken D, Hoek HW. Epidemiology of eating disorders: incidence, prevalence, and mortality rates. Curr Psychiatry Rep (2012) 14:406-14. doi:10.1007/s11920-012-0282-y

25. Swinburn BA, Sacks G, Hall KD, McPherson K, Finegood DT, Moodie ML, et al. The global obesity pandemic: shaped by global drivers and local environments. Lancet (2011) 378:804-14. doi:10.1016/S0140-6736(11)60813-1

26. Allman-Farinelli MA, Chey T, Bauman AE, Gill T, James WPT. Age, period and birth cohort effects on prevalence of overweight and obesity in Australian adults from 1990 to 2000. Eur J Clin Nutr (2008) 62:898-907. doi:10.1038/sj.ejcn.1602769

27. Wells JCK, Marphatia AA, Cole TJ, McCoy D. Associations of economic and gender inequality with global obesity prevalence: understanding the female excess. Soc Sci Med (2012) 75:482-90. doi:10.1016/j.socscimed.2012.03.029

28. Jacobsen BK, Njolstad I, Thune I, Wilsgaard T, Lochen ML, Schirmer H. Increase in weight in all birth cohorts in a general population. The Tromso Study, 1974-1994. Arch Intern Med (2001) 161:466-72. doi:10.1001/archinte. 161.3.466

29. Horgen KB, Brownell KD. Comparison of price change and health message interventions in promoting healthy food choices. Health Psychol (2002) 21:505-12. doi:10.1037/0278-6133.21.5.505

30. Toossi M. A century of change: the US labor force, 1950-2050. Mon Lab Rev (2002) 125:15-28.

31. Bengtson V, DeTerre E. Aging and family relations. Marriage Fam Rev (1980) 3:51-76. doi:10.1300/J002v03n01_03

32. Anonymous. Women in the Work Force. Female power. The Economist. (2009).

33. Brody EM. "Women in the middle" and family help to older people. Gerontologist (1981) 21:471-80. doi:10.1093/geront/21.5.471 
34. Andersen SH, Hansen LG. The rise and fall of divorce: a sociological extension of Becker's model of the marriage market. J Math Social (2012) 36:97-124. doi:10.1080/0022250X.2011.556768

35. Sypeck MF, Gray JJ, Ahrens AH. No longer just a pretty face: fashion magazines' depictions of ideal female beauty from 1959 to 1999. Int J Eat Disord (2004) 36:342-7. doi:10.1002/eat.20039

36. Mansfield L. "Sexercise": working out heterosexuality in Jane Fonda's fitness books. Leisure Stud (2011) 30:237-55. doi:10.1080/02614367.2010.523837

37. Sinha R, Fox H, Hong K-I, Sofuoglu M, Morgan PT, Bergquist KT. Sex steroid hormones, stress response, and drug craving in cocaine-dependent woman: implications for relapse susceptibility. Exp Clin Psychopharmacol (2007) 15:445-52. doi:10.1037/1064-1297.15.5.445

38. Bardone-Cone AM, Brownstone LM, Higgins MK, Harney MB, FitzsimmonsCraft EE. Predicting difficulties controlling overeating and drinking when experiencing negative affect in undergraduate women. J Soc Clin Psychol (2012) 31:1051-73. doi:10.1521/jscp.2012.31.10.1051

39. Trace SE, Thornton LM, Runfola CD, Lichtenstein P, Pedersen NL, Bulik CM. Sleep problems are associated with binge eating in women. Int J Eat Disord (2012) 45:695-703. doi:10.1002/eat.22003

40. Sinha R, Jastreboff AM. Stress as a common risk factor for obesity and addiction. Biol Psychiatry (2013) 73:827-35. doi:10.1016/j.biopsych.2013.01.032

41. Liang NC, Smith ME, Moran TH. Palatable food avoidance and acceptance learning with different stressors in female rats. Neuroscience (2013) 235:149-58. doi:10.1016/j.neuroscience.2012.12.068

42. Xu X, Tan L, Himi T, Sadamatsu M, Tsutsumi S, Akaike M, et al. Change preference for sweet taste in adulthood induced by perinatal exposure to bisphenol A-A probable link to overweight and obesity. Neurotoxicol Teratol (2011) 33:458-63. doi:10.1016/j.ntt.2011.06.002

43. Cason AM, Grigson PS. Prior access to a sweet is more protective against cocaine self-administration in female rats than in male rats. Physiol Behav (2013) 112113:96-103. doi:10.1016/j.physbeh.2013.02.017

44. Davis C, Fattore L, Kaplan AS, Carter JC, Levitan RD, Kennedy JL. The suppression of appetite and food consumption by methylphenidate: the moderating effects of gender and weight in healthy adults. Int J Neuropsychopharmacol (2012) 15:181-7. doi:10.1017/S1461145711001039

45. Bello NT, Hajnal A. Dopamine and binge eating behaviors. Pharmacol Biochem Behav (2010) 97:25-33. doi:10.1016/j.pbb.2010.04.016

46. Javaras KN, Laird NM, Reichborn-Kjennerud T, Bulik CM, Pope HG Jr, Hudson JI. Familiality and heritability of binge eating disorder: results of a casecontrol family study and a twin study. Int J Eat Disord (2008) 41:174-9. doi:10.1002/eat.20484

47. Popkin BM. Recent dynamics suggest selected countries catching up to US obesity. Am J Clin Nutr (2010) 91:284S-8S. doi:10.3945/ajcn.2009.28473C

48. Gibson EL. The psychology of comfort eating: implications for neuropharmacological interventions. Behav Pharmacol (2012) 23:442-60. doi:10.1097/FBP. 0b013e328357bd4e

49. Seo D, Jia Z, Lacadie CM, Tsou KA, Bergquist K, Sinha R. Sex differences in neural responses to stress and alcohol context cues. Hum Brain Mapp (2011) 32:1998-2013. doi:10.1002/hbm.21165

50. Sinha R, Garcia M, Paliwal P, Kreek MJ, Rounsaville BJ. Stress-induced cocaine craving and hypothalamic-pituitary-adrenal responses are predictive of cocaine relapse outcomes. Arch Gen Psychiatry (2006) 63:324-31. doi:10.1001/archpsyc.63.3.324

51. Bardo MT, Neisewander JL, Kelly TH. Individual differences and social influences on the neurobehavioral pharmacology of abused drugs. Pharmacol Rev (2013) 65:255-90. doi:10.1124/pr.111.005124

52. Seth P, Murray CC, Braxton ND, DiClemente RJ. The concrete jungle: city stress and substance abuse among young adult African American men. J Urban Health (2013) 90:307-13. doi:10.1007/s11524-012-9716-4

53. Wittchen HU, Jacobi F, Rehm J, Gustavsson A, Svensson M, Jonsson B, et al. The size and burden of mental disorders and other disorders of the brain in Europe 2010. Eur Neuropsychopharmacol (2011) 21:655-79. doi:10.1016/j.euroneuro. 2011.07.018

54. Becker JB. Sexual differentiation of motivation: a novel mechanism? Horm Behav (2009) 55:646-54. doi:10.1016/j.yhbeh.2009.03.014

55. Colell D, Sanchez-Niubo A, Domingo-Salvany A. Sex differences in the cumulative incidence of substance use by birth cohort. Int J Drug Policy (2013) 24:319-25. doi:10.1016/j.drugpo.2012.09.006
56. Elman I, Karlsgodt KH, Gastfriend DR. Gender differences in cocaine craving among non-treatment-seeking individuals with cocaine dependence. Am J Drug Alcohol Abuse (2001) 27:193-202. doi:10.1081/ADA100103705

57. Evans SM, Foltin RW. Does the response to cocaine differ as a function of sex of hormonal status in human and non-human primates? Horm Behav (2010) 58:13-21. doi:10.1016/j.yhbeh.2009.08.010

58. Back SE, Payne RL, Wahlquist AH, Carter RE, Stroud Z, Haynes L. Comparative profiles of men and women with opioid dependence: results from a national multisite effectiveness trial. Am J Drug Alcohol Abuse (2011) 37:313-23. doi:10.3109/00952990.2011.596982

59. Davis C, Levitan RD, Yilmaz Z, Kaplan AS, Carter JC, Kennedy JL. Binge eating disorder and the dopamine D2 receptor: genotypes and sub-phenotypes. Prog Neuropsychopharmacol Biol Psychiatry (2012) 38:328-35. doi:10.1016/j.pnpbp. 2012.05.002

60. Davis C, Levitan RD, Reid C, Carter JC, Kaplan AS, Patte K. Dopamine for "wanting" and opioids for "liking": a comparison of overweight/obese adults with and without binge eating disorder. Obesity (Silver Spring) (2009) 17:1220-5. doi:10.1038/oby.2009.52

61. Tanofsky-Kraff M, Bulik CM, Marcus MD, Striegel RH, Wilfley DE, Wonderlich SA, et al. Binge eating disorder: the next generation of research. Int J Eat Disord (2013) 46:193-207. doi:10.1002/eat.22089

62. Scheff T. A social/emotional theory of "mental illness". Int J Soc Psychiatry (2012) 59:87-92. doi:10.1177/0020764012445004

63. Chao YH, Yang CC, Chiou WB. Food as ego-protective remedy for people experiencing shame. Experimental evidence for a new perspective on weight-related shame. Appetite (2012) 59:570-5. doi:10.1016/j.appet.2012. 07.007

64. Dearing RL, Stuewig J, Tangney JP. On the importance of distinguishing shame from guilt: relation to problematic alcohol and drug use. Addict Behav (2005) 30:1392-404. doi:10.1016/j.addbeh.2005.02.002

65. Treeby M, Bruno R. Shame and guilt-proneness: divergent implications for problematic alcohol use and drinking to cope with anxiety and depression symptomatology. Pers Indiv Diff(2012) 53:613-7. doi:10.1016/j.paid.2012. 05.011

66. Allen KL, McLean NJ, Byrne SM. Evaluation of a new measure of mood tolerance, the tolerance of mood state scale (TOMS): psychometric properties and associations with eating disorder symptoms. Eat Behav (2012) 13:326-34. doi:10.1016/j.eatbeh.2012.05.005

67. Kozak AT, Fought A. Beyond alcohol and drug addiction: does the negative trait of low distress tolerance have an association with overeating? Appetite (2011) 57:578-81. doi:10.1016/j.appet.2011.07.008

68. Perkins A, Giedgowd GE, Karelitz JL, Conklin CA, Lerman C. Smoking in response to negative mood in men versus women as a function of distress tolerance. Nicotine Tob Res (2012) 14:1418-25. doi:10.1093/ntr/nts075

69. Leyro TM, Zvolensky MJ, Bernstein A. Distress tolerance and psychopathological symptoms and disorders: a review of the empirical literature among adults. Pyschol Bull (2010) 136:576-600. doi:10.1037/a0019712

70. Agrawal A, Lynskey MT. Are there genetic influences on addiction: evidence from family, adoption and twin studies. Addiction (2008) 103:1069-81. doi:10.1111/j.1360-0443.2008.02213.x

71. Davis JF, Loos M, Di Sebastiano AR, Brown JL, Lehman MN, Coolen LM. Lesions of the medial prefrontal cortex cause maladaptive sexual behavior in male rats. Biol Psychiatry (2010) 67:1199-204. doi:10.1016/j.biopsych.2009. 12.029

72. Davis C, Patte K, Curtis C, Reid C. Immediate pleasures and future consequences: a neuropsychological study of binge eating disorder and obesity. Appetite (2010) 54:208-13. doi:10.1016/j.appet.2009.11.002

73. Schag K, Schonleber J, Teufel M, Zipfel S, Giel K. Food-related impulsivity in obesity and binge eating disorder - a systematic review. Obes Rev (2013) 6:477-95. doi:10.1111/obr.12017

74. Duchesne M, Mattos P, Appolinario JC, de Freitas SR, Coutinho G, Santos $\mathrm{C}$, et al. Assessment of executive functions in obese individuals with binge eating disorder. Rev Bras Psiquiatr (2010) 32:381-8. doi:10.1590/S151644462010000400011

75. Haylett SA, Stephenson GM, Lefever RMH. A study of addictive orientations using the shorter-PROMID questionnaire. Addict Behav (2004) 29:61-71. doi:10.1016/S0306-4603(03)00083-2 
76. Wilfley DE, Friedman MA, Dounchis JZ, Stein RI, Welch RR, Ball SA. Comorbid psychopathology in binge eating disorder: relation to eating disorder severity at baseline and following treatment. J Consult Clin Psychol (2000) 68:641-9. doi:10.1037/0022-006X.68.4.641

77. Johnson PM, Kenny PJ. Dopamine D2 receptors in addiction-like reward dysfunction and compulsive eating in obese rats. Nat Neurosci (2010) 13:635-41. doi:10.1038/nn.2519

78. Lilenfeld LRR, Ringham R, Kalarchian MA, Marcus MD. A family history study of binge-eating disorder. Compr Psychiatry (2008) 49:247-54. doi:10.1016/j.comppsych.2007.10.001

79. Blomquist KK, Masheb RM, White MA, Grilo CM. Parental substance use history of overweight men and women with binge eating disorder is associated with distinct developmental trajectories and comorbid mood disorder. Compr Psychiatry (2011) 52:693-700. doi:10.1016/j.comppsych.2010.12.007

80. Grucza RA, Krueger RF, Racette SB, Norberg KE, Hipp PR, Bierut LJ. The emerging link between alcoholism risk and obesity in the United States. Arch Gen Psychiatry (2010) 67:1301-8. doi:10.1001/archgenpsychiatry.2010.155

81. Corwin RL, Avena NM, Boggiano MM. Feeding and reward: perspectives from three rat models of binge eating. Physiol Behav (2011) 104:87-97. doi:10.1016/j.physbeh.2011.04.041

82. Gearhardt AN, Yokum S, Orr PT, Stice E, Corbin WR, Brownell KD. Neural correlates of food addiction. Arch Gen Psychiatry (2011) 32:E1-9. doi:10.1001/ archgenpsychiatry.2011.32

83. Avena NM, Rada P, Hoebel BG. Evidence of sugar addiction: behavioral and neurochemical effects of intermittent, excessive sugar intake. Neurosci Biobehav $\operatorname{Rev}$ (2008) 32:20-39. doi:10.1016/j.neubiorev.2007.04.019

84. Gearhardt AN, Corbin WR, Brownell KD. Preliminary validation of the Yale food addiction scale. Appetite (2009) 52:430-6. doi:10.1016/j.appet.2008. 12.003

85. Davis C, Curtis C, Levitan RD, Carter JC, Kaplan AS, Kennedy JL. Evidence that "food addiction" is a valid phenotype of obesity. Appetite (2011) 57:711-7. doi:10.1016/j.appet.2011.08.017

86. Gearhardt AN, White MA, Masheb RM, Morgan PT, Crosby RD, Grilo CM. An examination of the food addiction construct in obese patients with binge eating disorder. Int J Eat Disord (2012) 45:657-63. doi:10.1002/eat.20957

87. Cassin SE, von Ranson KM. Is binge eating experienced as an addiction? Appetite (2007) 49:687-90. doi:10.1016/j.appet.2007.06.012

88. Curtis C, Davis C. A qualitative study of binge eating disorder and obesity from an addiction perspective. Eat Disord J Treat Prev (2014) 22:1-14. doi:10.1080/10640266.2014.857515

89. Davis C. Compulsive overeating as an addictive behavior: overlap between food addiction and binge eating disorder. Curr Obes Rep (2013) 2:171-8. doi:10.1007/s13679-013-0049-8

90. Burmeister JM, Hinman N, Koball A, Hoffmann DA, Carels RA. Food addiction in adults seeking weight loss treatment. Implications for psychosocial health and weight loss. Appetite (2013) 60:103-10. doi:10.1016/j.appet.2012. 09.013

91. Foster RG, Roenneberg T. Human responses to the geophysical daily, annual and lunar cycles. Curr Biol (2008) 18:R784-94. doi:10.1016/j.cub.2008.07.003

92. Davidson AJ, Yamazaki S, Menaker M. SCN: ringmaster of the circadian circus or conductor of the circadian orchestra? Novartis Found Symp (2003) 253:110-21. doi:10.1002/0470090839.ch9

93. Sorg BA, Stark G, Sergeeva A, Jansen HT. Photoperiodic suppression of drug reinstatement. Neuroscience (2011) 176:284-95. doi:10.1016/j.neuroscience. 2010.12.022

94. Bronson EH. Are humans seasonally photoperiodic? J Biol Rhythms (2004) 19:180-92. doi:10.1177/0748730404264658
95. Avery DH, Bolte MA, Ries R. Dawn simulation treatment of abstinent alcoholics with winter depression. J Clin Psychiatry (1998) 59:36-42. doi:10.4088/ JCP.v59n0109

96. Sher L. Alcoholism and seasonal affective disorder. Compr Psychiatry (2004) 45:51-6. doi:10.1016/j.comppsych.2003.09.007

97. Kovanen L, Saarikoski ST, Haukka J, Pirkola S, Aromaa A, Lonnqvist J, et al. Circadian clock gene polymorphisms in alcohol use disorders and alcohol consumption. Alcohol Alcohol (2010) 45:303-11. doi:10.1093/alcalc/agq035

98. Cecinato A, Balducci C, Romagnoli P, Perilli M. Airborne psychotropic substances in eight Italian big cities: burdens and behaviours. Environ Pollut (2012) 171:140-7. doi:10.1016/j.envpol.2012.07.033

99. Falcon E, McClung CA. A role for the circadian genes in drug addiction. Neuropharmacology (2009) 56:91-6. doi:10.1016/j.neuropharm.2008.06.054

100. McClung CA. Circadian genes, rhythms and the biology of mood disorders. Pharmacol Ther (2007) 114:222-32. doi:10.1016/j.pharmthera.2007.02.003

101. Ayers JW, Althouse BM, Allem JP. Seasonality in seeking mental health information on Google. Am J Prev Med (2013) 44:520-5. doi:10.1016/j.amepre.2013. 01.012

102. Halmi KA, Falk JR, Schwartz E. Binge eating and vomiting: a survey of a college population. Psychol Med (1981) 11:697-706. doi:10.1017/S0033291700041192

103. Christo G, Jones SI, Haylett S, Stephenson GM, Lefever RMH, Lefever R. The shorter PROMIS questionnaire: further validation of a tool for simultaneous assessment of multiple addictive behaviours. Addict Behav (2003) 28:225-48. doi:10.1016/S0306-4603(01)00231-3

104. Eysenck HJ, Eysenck SBG. Manual of the Eysenck Personality Questionnaire. London: Hodder \& Stoughton (1975).

105. Rosenthal NE, Bradt GH, Wehr TA. Seasonal Pattern Assessment Questionnaire (SPAQ). Bethesda: National Institute of Mental Health (1984).

106. Torrubia R, Avila C, Molto J, Caseras X. The sensitivity to punishment and sensitivity to reward questionnaire (SPSRQ) as a measure of Gray's anxiety and impulsivity dimensions. Pers Indiv Diff(2002) 31:837-62. doi:10.1016/S01918869(00)00183-5

107. Avena NM, Murray S, Gold MS. Comparing the effects of food restriction and overeating on brain reward systems. Exper Gerontol (2013) 48:1062-7. doi:10.1016/j.exger.2013.03.006

108. Volkow ND, Wang GJ, Fowler JS, Logan J, Gatley SJ, MacGregor RR. Measuring age-related changes in dopamine D-2 receptors with C-11-raclopride and F-18-N-methylspiroperidol. Psychiatry Res (1996) 67:11-7. doi:10.1016/09254927(96)02809-0

Conflict of Interest Statement: The author declares that the research was conducted in the absence of any commercial or financial relationships that could be construed as a potential conflict of interest.

Received: 06 September 2013; accepted: 14 December 2013; published online: 27 December 2013.

Citation: Davis C (2013) A narrative review of binge eating and addictive behaviors: shared associations with seasonality and personality factors. Front. Psychiatry 4:183. doi: 10.3389/fpsyt.2013.00183

This article was submitted to Eating Behavior, a section of the journal Frontiers in Psychiatry.

Copyright (c) 2013 Davis. This is an open-access article distributed under the terms of the Creative Commons Attribution License (CC BY). The use, distribution or reproduction in other forums is permitted, provided the original author(s) or licensor are credited and that the original publication in this journal is cited, in accordance with accepted academic practice. No use, distribution or reproduction is permitted which does not comply with these terms. 